\title{
The consequence of magnetic field on the parameters of brackish water in batch and continuous flow system
}

\author{
Ashraf M. El-Shamy ${ }^{1 *}$ (D, Ahmed Abdo², Elshafie A. M. Gad ${ }^{3}$, Amr A. Gado ${ }^{4}$ and Emad El-Kashef ${ }^{5}$
}

\begin{abstract}
Background: The concept of magnetized water and the historically abbreviated glimpse were discussed. Therefore, the magnetic water treatment method has been summed up and considered a better and cleaner physical technique for water handling. This experimental work is focused on the effect of magnetic treatment on certain water parameters such as temperature, electrical conductivity (EC), total dissolved salts (TDS), and pH by exposing water to a permanent magnetic field (PMF) with a magnetic flux density $(B=1.45 T \pm 0.05)$.

Results: This technique is realized by using a fixed system that depends on the application of both pump and valve control to induce the required circulation of employed water. Both open loop and closed loop are applied as a function of exposure time. Considering that the type of used water is brackish groundwater. The results showed that at open and closed flow conditions, the PMF causes variations in the values of the measured parameters for the outflow water. The theoretical approach is subjected to measure the molecular interaction of water system $\mathrm{H}$-bonded systems based on DFT level with function B3LYP on Gaussian 09 software with a specific concentration of $\mathrm{NaCl}$. This research focuses on the relation between the molecular structure of water and the dissolved $\mathrm{NaCl}$ with respect to applying a magnetic field with a varying force from 1 to $85 \mathrm{~T}$.
\end{abstract}

Conclusion: The water's magnetization technique is simple without using extra energy by using a PWT tool to create a permanent magnetic field $(B=1.45 \mathrm{~T} \pm 0.05)$ when installing it on a water tube system that was previously mounted. This environmentally friendly, renewable technology, therefore, does not need any additional energy requirements.

Keywords: Modeling framework, Electrical conductivity measurements, Flow rate conditions, Magnetic field, Brackish groundwater

\section{Background}

The water supply deficit is an important factor in preventing boosted agricultural development and food security and is also one of the key issues that we are currently facing alongside the question of boosting food demand to cover humanitarian needs. Sustainable agricultural evolution is also influenced by the availability of water that

\footnotetext{
*Correspondence: elshamy10@yahoo.com

${ }^{1}$ Electrochemistry and Corrosion Laboratory, Physical Chemistry Department, National Research Centre, El-Bohouth St. 33, Dokki, P.O.

12622, Giza, Egypt

Full list of author information is available at the end of the article
}

could be used efficiently and effectively in the production of agricultural programs (Wang et al. 2018; Ambashtaa and Sillanpaa 2010; Iwasaka and Ueno 1998). Water is familiarly composed of clusters in this sense, and the more stable numbers of clusters are called magic numbers. The sequence of magic numbers contains fundamental knowledge about the cluster's electronic and ionic composition and thus the water characteristics. If it can make partial or slight improvements to the magic numbers, usually to boost them, we can get a lot of new water uses (Cho and Lee 2005; Zaidi et al. 2014; Rajput et al. 2016). While chemical additives have a great success rate in water treatment, their use is correlated with numerous 
unfavorable circumstances that minimize the chances of their effectiveness (Rajput et al. 2016). More stringent environmental regulations have increased the packaging, handling, and disposal costs involved (Sheikholeslami et al. 2016). Consequently, the environmental and economic concerns associated with conventional chemical water treatments are the vigorous explanation for introducing safer and healthier physical techniques such as magnetic water treatment, recognizing that the physical alteration in water during the application of a magnetic field is the alteration that happens without altering its chemical composition (Hachicha et al. 2018; Zlotopolsk 2017; Andrianov and Orlov 2018). In the presence of an applied external magnetic field, as larger water clusters are broken down to form a smaller cluster, more robust water structures would be generated to get new stable arrangements (Esmaeilnezhad et al. 2017). The magnetic field can be generated by using two kinds of devices, one of which uses permanent magnets, while the other is centered on AC or pulsed fields which are called alternating magnetic fields and ideally perpendicular to water flow direction (Liu et al. 2008; Tomska and Wolny 2008; Dickinson and McGrath 2004; Park et al. 2004; Tai et al. 2008). The technique of magnetic water treatment is usually to move water at a particular velocity via a magnetic field. Water loses its ability to precipitate hardness salts in the form of scale after such treatment, and these salts are crystallized as precise sludge easily transported by the water flow (Alim 2009; Bogatin et al. 1999; Donaldson 1988). Although numerous researchers have asserted the magnetic field's impact on water, some others still disprove the effect. It is understood that surface tension is one of the characteristics of water that is very sensitive to empirical conditions. As the temperature of the water increases, it was observed that its surface tension decreases. Because of this, water treatment is a method magnetically used to reduce water surface tension (Wang et al. 1997). No significant evidence between both surface tension and magnetic field effect on it when the velocity of circulation of water in this magnetic field is elevated during the water magnetization process. The explanation for this is that under an elevated velocity the time is too short for magnetization, in addition, the water molecules are highly disoriented, and this adds to the difficulties of magnetizing the water (Pandolfo et al. 1987). The surface tension of tap water at a temperate velocity will diminish after magnetization. The experimental study investigated the effect of applying a magnetic field to saltwater that was prepared in the laboratory using $\mathrm{NaCl}$ with total dissolved solids TDS approximately equal to $1890 \mathrm{ppm}$ and was then pumped through a magnetic field from a $25-\mathrm{L}$ tank using a pump with a maximum flow rate of $4 \mathrm{~m}^{3} / \mathrm{h}$ and $0.25 \mathrm{~m}^{3} / \mathrm{h}$ as minimum flow rate. It has been observed that TDS of this saltwater varies at different times $20,40,60,80,100$, and $120 \mathrm{~min}$. in a closed period in which TDS decreased due to the impact of applying this magnetic field to this saltwater, realizing that this effect depends on the time of exposure to the magnetic field in which TDS decreased by about 32.8 percent in $2 \mathrm{~h}$ (Watt et al. 1993; Hogan et al. 1994). The magnetic field influence was highest with lower salinity and higher $\mathrm{pH}$, while magnetic influence was lower with low and high $\mathrm{pH}$ and salinity, respectively, and the presence of salt, the power of the magnetic field is weaker. Hard water is considered to have various negative domestic, industrial, and agricultural effects as it is water that contains a high mineral content in which the amount of all minerals thawed in water is defined as TDS. It is important to keep an eye on the level of total dissolved solids in water. To put it plainly, TDS consists of inorganic salts and organic matter which has dissolved in water. The different forms of TDS include essentially calcium, magnesium, potassium, sodium, bicarbonates, chlorides, iron, lead, and sulfates (Paiaro and Pandolfo 1994; Golovleva et al. 2000; Mosin and Ignatov 2015). It is understood that calcium typically comes into the water in the form of either calcium carbonate $\mathrm{CaCO}_{3}$ in the form of calcareous and chalk, or calcium sulfate $\mathrm{CaSO}_{4}$ in the form of various other mineral sediments, while dolomite $\mathrm{CaMg}\left(\mathrm{CO}_{3}\right)_{2}$ is the main source of magnesium. Based on the previous behavior, a specified volume of TDS is in water that occurs naturally as it flows through the soil. But when a storm hits or sewage pollution occurs, the level of the dissolved solids starts to reach an unacceptable, potentially harmful level (Nakagawa et al. 1999). Scale is formed because of the hardness of the water. It was discovered that limescale decreases pipeline diameter, which in turn improves flow resistance, leading to a negative impact on heat exchange system operation (Yamashita et al. 2003). As a result, additional monetary expenditures are required to scour the limescale steam boilers, heat exchangers, and other heat-exchange devices by perpetual repairs, in addition to repairing the piping and plumbing. Further, a various experimental work was aimed at handling hard water using magnetic techniques (Kozic and Lipus 2003). Antiscale magnetic water treatment for steam boilers, heat exchangers, has been the most prevalent. The effect of the magnetic field on aqueous solutions will decrease the scale rate in pipes and on heat exchanger surfaces if the effect of magnetic water treatment does not reach the appropriate range of values of the scale of soluble calcium and magnesium salts (Guo et al. 2012). Thus, in the case of using magnetic water, the anti-scale effect relies on other variables during the construction of a magnetic water treatment system, such as a sufficiently strong magnetic field with proper flux distribution, the rate of 
water movement, the length of its magnetic field stays, magnet location and the composition of the treated water (Baker and Judd 1995). It should be considered that the effect of magnetic treatment often depends on the properties of the pipe, in which the degree of that effect depends on the conductivity of the pipe and the roughness of the surface. Therefore, it is understood that all elements of the environment interact with each other interactively, including all living human, plant, and animal species. Such species are affected by the environmental factors in the air, water, and soil that surround them (Amor et al. 2018). Those living organisms are known to benefit from enhanced water properties. From the above, using the magnetic field to magnetize water induces certain variations in its properties, making it more beneficial under using (Alimi 2008). In various fields, such as irrigation, plant production, plant productivity, and animal science, the technicality of magnetic water treatment has advanced rapidly (Elaoud et al. 2016). The use of an external magnetic field plays an effective role in water molecules, in which some of them can break away from the cluster of water molecules and become free monomer molecules (Kotb and Aziz 2013; Jiang et al. 2015; Zohdy et al. 2021; Shehata et al. 2019; 2020; Emad et al. 2019; Farag et al. 2016).

\section{Methods}

The experimental system is in the National Research Center, where a quantity of brackish groundwater was supplied there to investigate the magnetic field's effect on it. It should be known that the action of the magnetic field on stationary water is considerably weaker, because moving in flux water has some electro-conductivity, whereas moving in the magnetic field causes small electrical currents. Despite this, both the pump and the valve contribute to increased turbidity of flowing water. In addition to the shape and design of the permanent water treatment (PWT) unit, the nature of the pump used is the same as the effect of magnetic treatment of potable water in looped and dead-end water networks described in the research paper.

\section{Exposure to magnets}

The length of the hose used, in connection with the pump used, is approximately $150 \mathrm{~cm}$ with a diameter of approximately $2.5 \mathrm{~cm}$. Another piece of plastic hose with the same prior measurement's diameter of $2.5 \mathrm{~cm}$, length $150 \mathrm{~cm}$ was connected to the PWT device. PWT system was utilized in a series of experiments to test its effect on the quantity of brackish groundwater supplied here. All water samples were examined for instant measurement of temperature, electrical conductivity (EC), total dissolved solids (TDS), and pH in an open loop. Additionally, in the case of a closed loop, these water parameters were also studied as time functions.

\section{Measurements}

The samples of the water analyzed were mounted in a glass beaker in accordance with the apparatus electrode (HANNA instruments HI98310), in which it is used to calculate the values of the prior water parameters for the inflow before its entry into the PWT system and for the outflow after its exit. For this purpose, the PWT system is used to establish a permanent magnetic field with a density of magnetic flux $(B=1.45 \mathrm{~T} \pm 0.05)$.

\section{Computational Methodology}

Density functional theory (DFT) level with (B3LYP) was used to estimate hydrogen bond energy $(\mathrm{eV})$ of water molecules at different concentrations (ppm) of $\mathrm{NaCl}$. On the ground-state PES (potential energy surface), the effect of the external apparent magnetic field was studied using single-point energy calculations for water molecules. The applied magnetic field intensities are in the range of 0 to $85 \mathrm{~T}$. The energy of molecular interaction is estimated using the equation below.

$$
\Delta E_{H B}=\left(E_{(\mathrm{H} 2 \mathrm{O}) n}+E_{\mathrm{NaCl}}\right)_{\text {unbonded }}-E_{[\mathrm{H} 2 \mathrm{O}) n+\mathrm{NaCl}] \text { bonded }}
$$

where $\Delta E_{H \mathrm{~B}}$ is the intra-binding energy for the water molecules, $E_{(\mathrm{H} 2 \mathrm{O}) n}$ and $E_{\mathrm{NaCl}}$ are the energies of water and $\mathrm{NaCl}$ molecules as a separate phases. $E_{[\mathrm{H} 2 \mathrm{O}) n+\mathrm{NaCl}]}$ is the energy of the combined system water and $\mathrm{NaCl}$.

\section{Results}

The relation of magnetic field and the increasing plant growth using magnetized water is discussed. The mode of action is concerned with rational reasoning, which gets monomer water molecules that can permeate easily across biological cell walls. Irrigating a plant with only high salinity water or mixing it with low salinity water is an increasing problem in many regions around the world because this will lead to an increase in soil salinity, particularly on the surface of the soil layer, resulting in a decrease in vegetable and crop production in general, particularly in semiarid regions where irrigation water is present. Although brackish water can be classified as one of the types of waters where its salinity (TDS) is up to $15,000 \mathrm{ppm}$, it has been found that improvement in plant growth parameters has been boosted until $6000 \mathrm{ppm}$ of magnetic water has been treated. Despite this, magnetic treatment of water is a method used worldwide to resolve water salinity disorders. The results proved that the magnetic water treatment alters the distribution of salts across soil layers, reducing their content in the top layers where will be more important for agricultural activity. 
It has been highlighted that the treatment of magnetic water will eliminate $50 \%$ of soil salinity (El-Shamy et al. 2017; Essa et al. 2018). It should be noted that the degree of efficacy of magnetized water on soil salinity depended heavily on the magnetized water's traveling distance along irrigation network lines. It may be reasonable to assume that if scientific studies have confirmed that the treatment of magnetic water has health benefits for animals, it should also be useful for humans. Even in the years of the BC period, it is said that a lodestone or natural magnet was used by the legendary Cleopatra to sleep on it to preserve its prettiness and youthfulness. This has now been concluded that using the magnetic therapy technique does not give the illusion of being an alternative to the standard therapies in reducing ache, and this technique is only effective in reducing muscle aches. It should be remembered that during water treatment with magnetic fields such as magnetic impurities, various conditions are difficult to control. However, when exposed to the magnetic field using direct experimental techniques, it is difficult to analyze the changes that occur in the structure of water. Performing the theoretical calculations is thus an important way to overcome this problem (Reda et al. 2020a, b). The advances in computing trigger more accurate theoretical calculations. Remember that a strong magnetic field (14 $\mathrm{T}$ ) can affect the hydrogen bond structure of water molecules. Still, there is no ultimate point of view on the process of how aqueous solutions are influenced by magnetic fields. It has been noted that the hydrogen bond has greater stability in a magnetic field that can be enhanced which is the fundamental explanation for certain water characteristics alteration. The increase of approximately $0.34 \% \mathrm{t}$ in the number of hydrogen bonds can be accomplished if the strength of the magnetic field increases from 1 to $10 \mathrm{~T}$ since, a 10-T field is approximately 200,000 times the strength of the earth's magnetic field, which indicates that the ability to network water can be encouraged by the magnetic field, recognizing that 1.5, 3 and some $4 \mathrm{~T}$ magnets are used for magnetic fields. A greater number of hydrogen bonds indicate that the size of the water cluster boosts throughout the existence of a magnetic field; therefore, the composition of the water molecules becomes more organized and stable in the existence of a magnetic field. The average number of hydrogen bonds boosts in case a solution with a low concentration of $\mathrm{NaCl}$ is subjected to a magnetic field, but it declines in a high concentration solution and presented the fundamental truth of magnetic water treatment, in which each ion feels a Lorentz force as water can pass through a magnetic field (ElShamy et al. 2018). Owing to the redirection of particles, the frequency of collisions between ions raises, positive and negative ions combine to produce an insoluble compound; thus, calcium carbonates dispatched as slime from the solution that can easily be removed from the water. It is clearly noticed that weaker bonding with hydrogen is obtained by improving magnetized time so three hypotheses relating to the magnetized water process are set as follows: firstly, decomposition of colloidal metal ion complexes occurs in magnetized water, which accelerates their subsequent deposition. Secondly, the polarization of dissolved ions, e.g., $\mathrm{Na}^{+}$and $\mathrm{Cl}^{-}$, in water during magnetic field application and deformation of their hydration shells is shown in Fig. 1. Finally, the magnetic field influences the water structure in which the hydrogen bonds can be skewed and partly broken (ElShamy et al. 2020; Mohamed et al. 2020). The magnetic field splits the hydrogen bonds in the intra-cluster, causing a breakup in the larger clusters, resulting in smaller clusters with stronger inter-cluster hydrogen bonds, as shown in Fig. 2.

In other words, in the presence of an external magnetic field the size of a water cluster can be dominated. This then causes the mean size of water clusters to decrease, as shown in Fig. 3.

In Fig. 4, the schematic diagram for the experimental setup is given. Understanding that $\mathrm{S} 1$ indicates the water sample that was immediately checked in the open-loop system (1-8), while S2 indicates the water samples that were checked in the recirculating method at various periods of time. For two cases, the water treatment system experiments were conducted at room temperature $23 \pm 1{ }^{\circ} \mathrm{C}$ : (a) open loop and (B) closed or recirculating loop. In the case of using an open loop, the direction of inflow begins at a large tank included a quantity of brackish groundwater supplied here for this experiment. In addition to another plastic hose which is connected between this pump and PWT device, a plastic hose is connected between this tank and the pump used, knowing that this pump is used to move the inflow from this tank to the PWT device, as stated in Fig. 5. Table 1 shows the measurable parameters for the inflow of water used. But if a closed loop is used, the direction of inflow starts at the reservoir and ends at it. Brackish groundwater was exposed to a static magnetic field created from a permanent water treatment (PWT) system, in which a sample of outflow water was taken at a higher and lower flow rate and its parameter values (temperature, EC, TDS, and $\mathrm{pH}$ ) were calculated instantly during the passage of water through this system. The data obtained are epitomized in Table 2. It has been observed that the values of the collected data are fluctuating as compared to the calculated values of the parameters of the inflow. Additionally, the outflow temperature at the higher flow rate is greater than the outflow temperature at the lower flow rate. In the case 


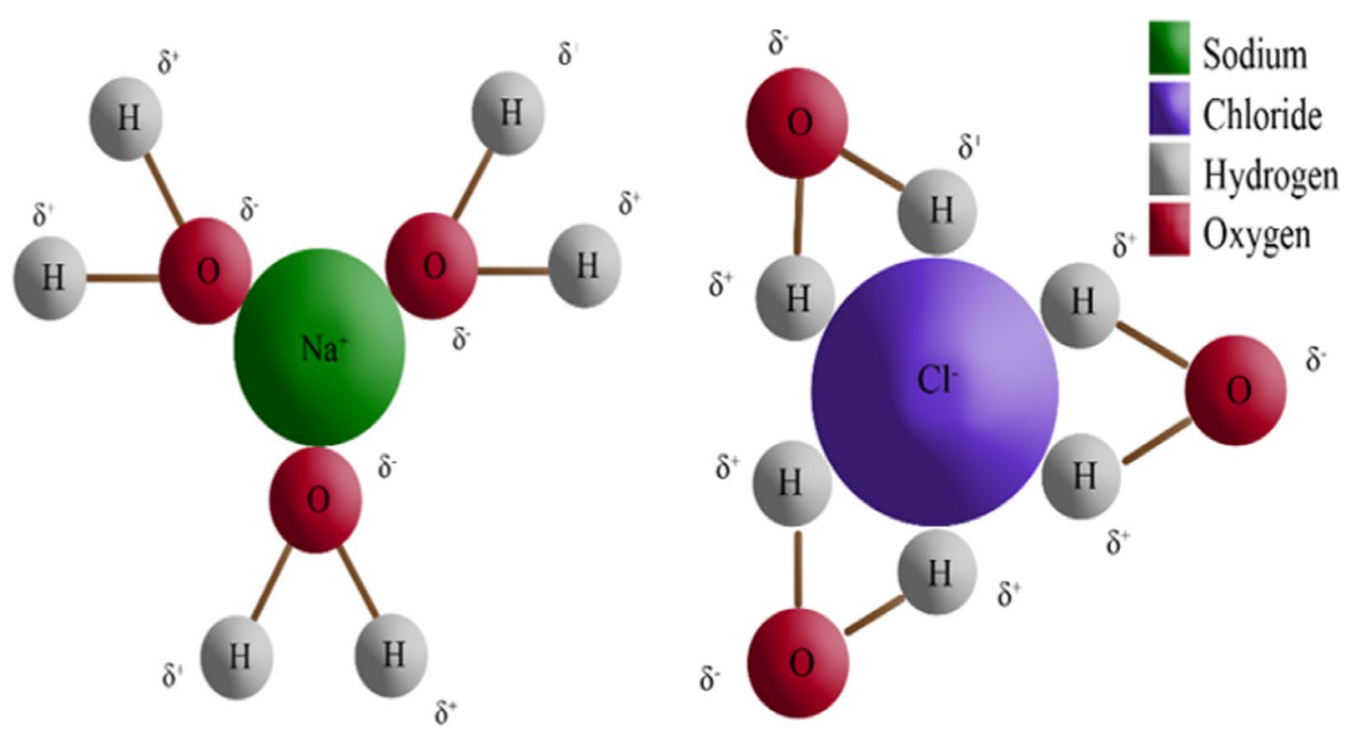

Fig. 1 A schematic diagram refers to the ions of sodium $\left(\mathrm{Na}^{+}\right)$and chloride $\left(\mathrm{Cl}^{-}\right)$while getting away from each other, in addition to the deformation of their hydration shells in water during the application of a magnetic field

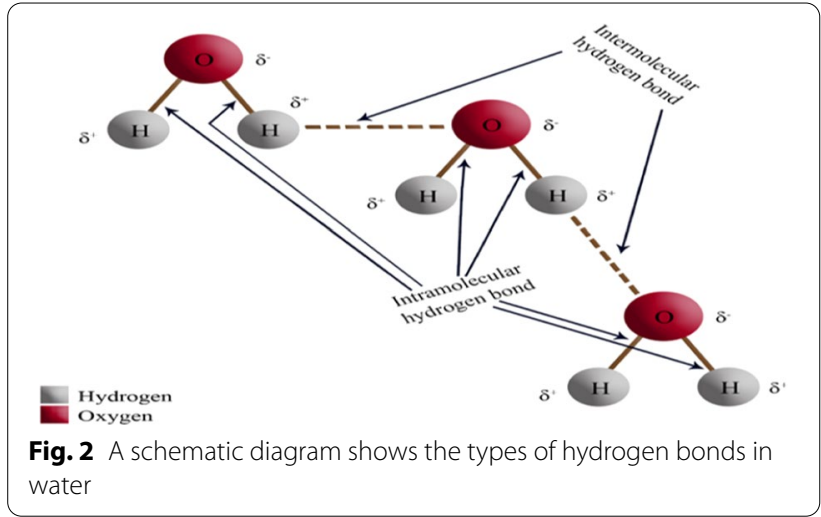

of the closed-loop method, these prior parameters were also analyzed as a function of time at the same higher and lower flow rate for extra visualization.

\section{Brackish groundwater parameters in recirculating system (closed loop) Effect of contact time}

At a higher and lower flow rate of $52.16 \mathrm{l} / \mathrm{min}$ and $12.32 \mathrm{l} / \mathrm{min}$, the brackish groundwater is passed through the PWT system for 5, 10, 15, 20, and $25 \mathrm{~min}$, respectively, at incremental times. A sample of the outflow water was taken after each period, and its parameters were immediately determined. The parameters measured are temperature, electrical conductivity, total dissolved solids, and $\mathrm{pH}$. In addition to the use of
Microsoft Excel, the data obtained were exposed to a theoretical approach by using MATLAB R2013a to find the convenient polynomial equation for this treatment condition.

\section{Outflow temperature}

One of three crucial points was found to be 24.11. Therefore, since the function increases to the left and decreases to the right of 24.11 , it must be that 24.11 is a maximum locale. It should be noted that as the incremental time periods rise from 30 to $75 \mathrm{~min}$, it was found that the outflow temperature rises at a flow rate of $52.16 \mathrm{l} / \mathrm{min}$ as shown in Figs. 6, 7, 8 and 9.

\section{Outflow (EC and TDS)}

It was found that there are three crucial points where 6.97 and 22.80 are maximum local but 2.71 is a minimum local. It should be noted that as the incremental time periods increase from 30 to $75 \mathrm{~min}$, the outflow for both EC and TDS decreases at a flow rate of $52.16 \mathrm{l} /$ min as shown in Figs. 10 and 11. Compared to the inflow TDS (940 ppm), if the outflow TDS (800 ppm) at $75 \mathrm{~min}$ is compared to the inflow TDS (940 ppm), it has been observed that the inflow TDS value is down quite marginally, around $140 \mathrm{ppm}$. Hence, in this case, the percentage variation between both the inflow and the outflow is about (14.89\%).

\section{Outflow $p H$}

Figure $12 \mathrm{~A}$ shows the relationship between $\mathrm{pH}$ vs. flow rate $52.16 \mathrm{l} / \mathrm{min}$., and we can see three critical points: 


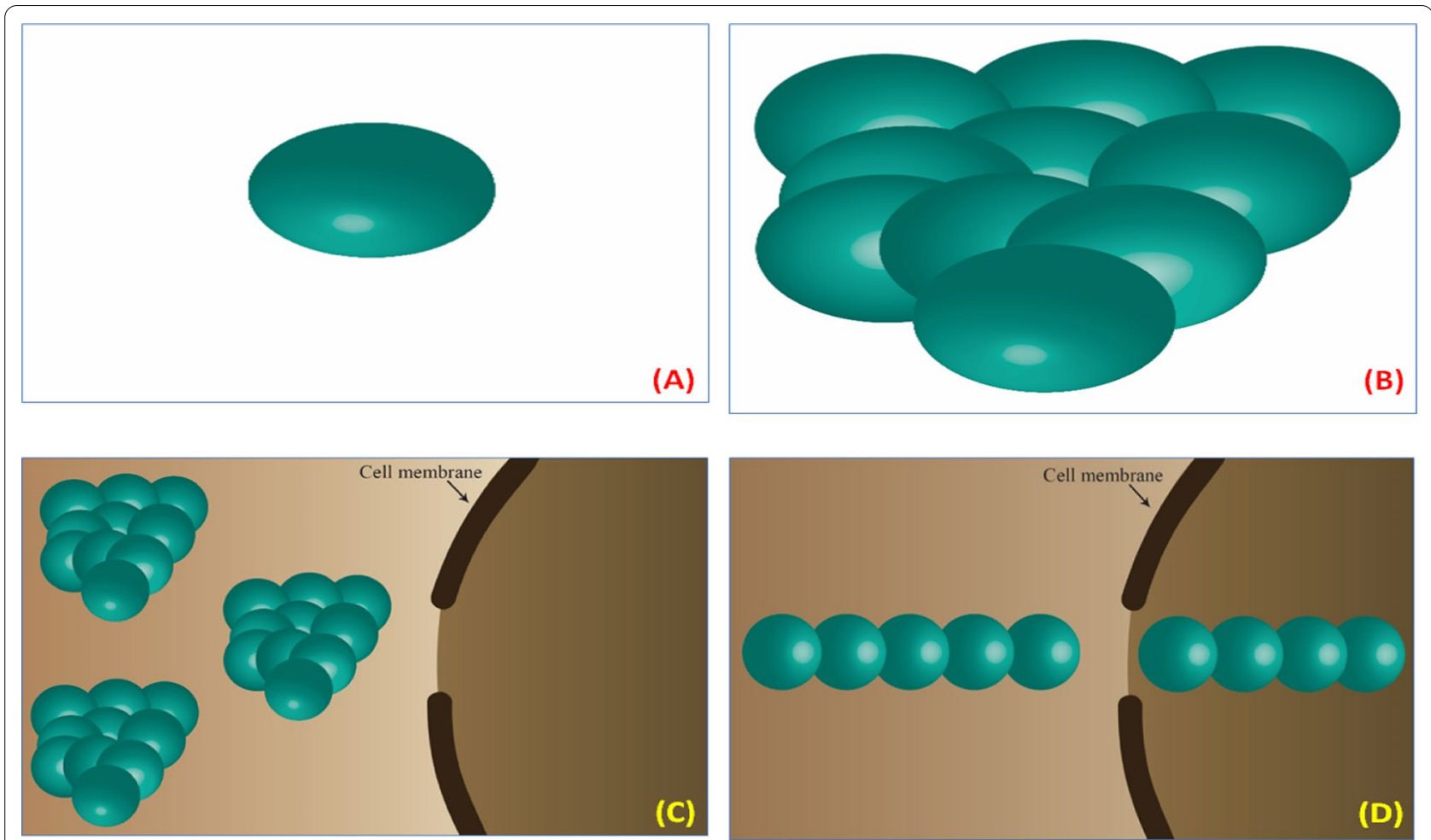

Fig. 3 A A schematic diagram shows the assumption shape of a water cluster. B A collective of some water clusters together. C Non-magnetized water clusters have hitches during passing through plant capillaries and cell walls. D Magnetized water clusters enter the plant capillaries and cell walls readily

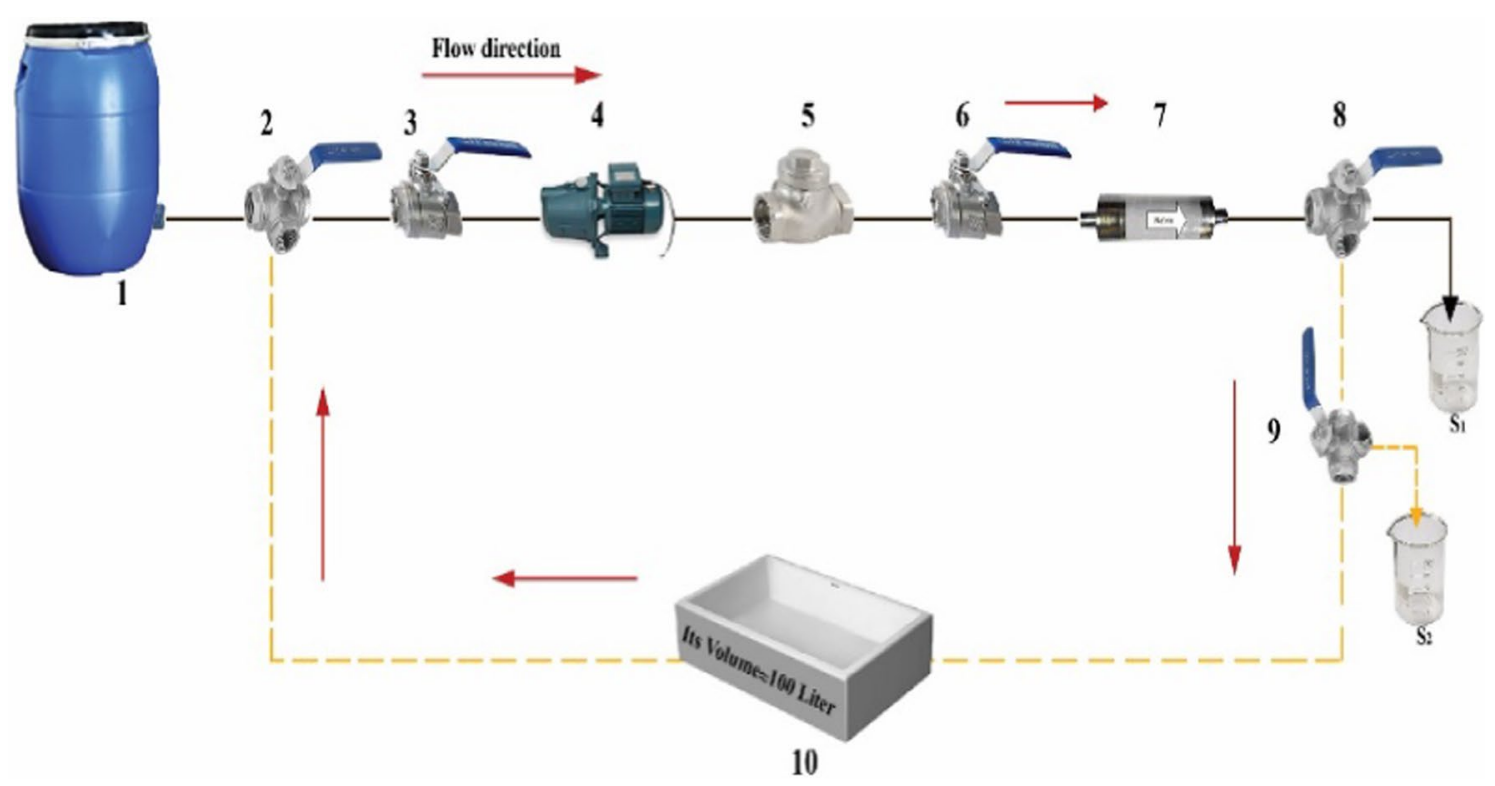

Fig. 4 The schematic diagram of permanent magnetic field PMT system. Where (1) Tank: contains a quantity of brackish groundwater that was supplied here for this experiment. (2) Three-way ball valve shuts off the water flow in one direction and opens it in another direction. (3) Gate valve (ball valve, 2 ports): normally open. (4) Centrifugal pump. (5) Check valve (swing check valve, 1 inch): non-return valve used to protect the pump from backflow. (6) Gate valve (ball valve, 2 ports): throttling the flow rate. (7) PWT device: used for treating brackish groundwater (salt content up to $3000 \mathrm{ppm} \pm 500$ ). (8) Three-way valve. (9) Three-way valve. (10) Reservoir. 


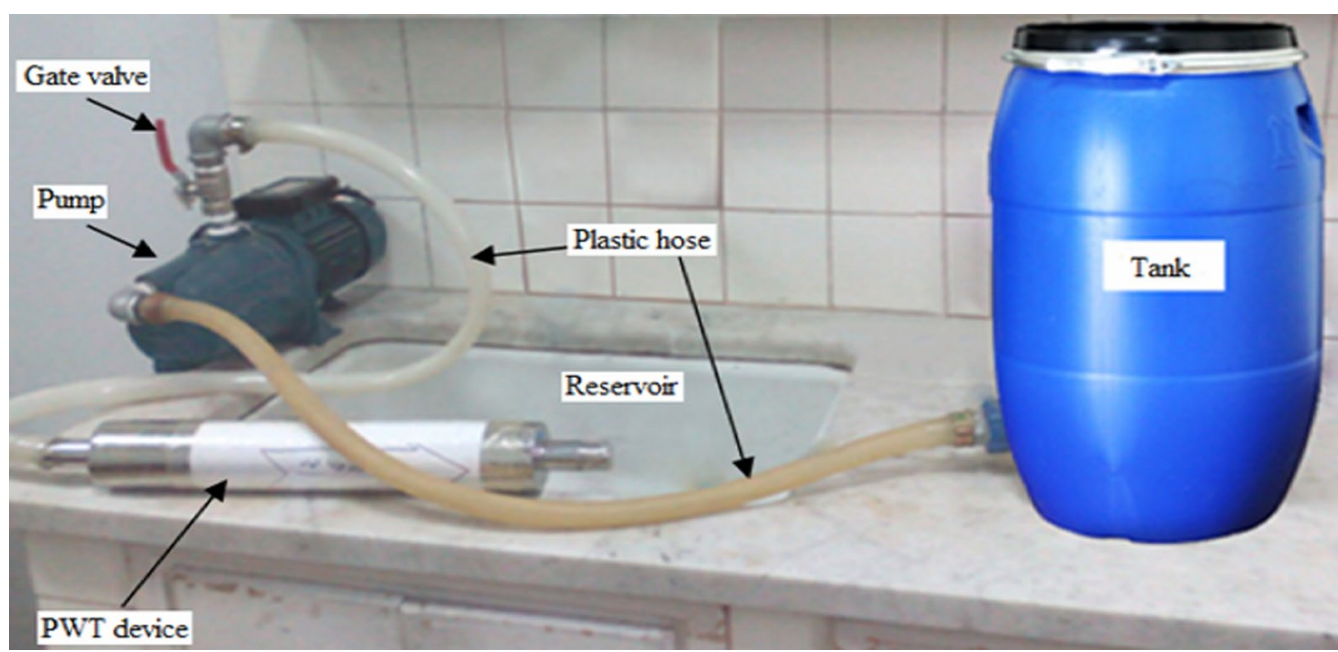

Fig. 5 Water treatment system in case of using open loop

Table 1 The measurable parameters for inflow used water

\begin{tabular}{llll}
\hline $\boldsymbol{T}\left({ }^{\circ} \mathrm{C}\right)$ & $\mathrm{EC}(\boldsymbol{\mu S} / \mathrm{cm})$ & TDS $(\mathrm{ppm})$ & $\mathrm{pH}$ \\
\hline 24.1 & 1870 & 940 & 8.90
\end{tabular}

Table 2 The measurable parameters instantly for outflow brackish groundwater at two different pumps 's flow rates

\begin{tabular}{lllll}
\hline Flow rate $(\mathrm{L} / \mathrm{min})$ & $\boldsymbol{T}\left({ }^{\circ} \mathrm{C}\right)$ & $\mathrm{EC}(\boldsymbol{\mu S} / \mathrm{cm})$ & $\mathrm{TDS}(\mathrm{ppm})$ & $\mathrm{pH}$ \\
\hline 52.16 & 26.5 & 1850 & 920 & 7.93 \\
12.32 & 24.6 & 1850 & 920 & 8.89 \\
\hline
\end{tabular}

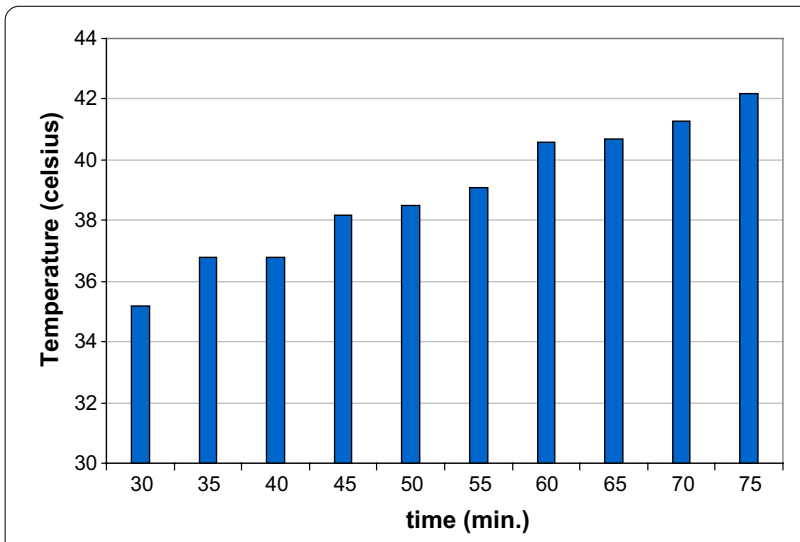

Fig. 6 Temperature vs. time (30 min. up to $75 \mathrm{~min}$ ), by using brackish groundwater in case of closed cycle at flow rate of $52.16 \mathrm{l} / \mathrm{min}$
8.62, 15.21, and 23.81. Therefore, since the function decreases to the left and grows to the right of 8.62 , it must be that 8.62 is a local minimum. Therefore, the feature increases to the left and decreases to the right of 15.21 , and it may be that 15.21 is a maximum locale. Furthermore, the feature decreases to the left and rises to the right of 23.81; it must be that 23.81 is a local minimum. It should be noted that as the incremental time periods increase from 30 to $75 \mathrm{~min}$, it was discovered that the outflow $\mathrm{pH}$ fluctuates at a flow rate of $52.16 \mathrm{l} / \mathrm{min}$ as shown in Fig. 13.

\section{Outflow temperature and its relationship with the other outflow parameters}

It has been observed that in Fig. 14 there are variations in the values of the outflow water parameters EC, TDS, and $\mathrm{pH}$ with the variability of the outflow temperature values during the usage of the PWT system at different exposure times. The number of ions rises with the breakdown of molecules. Temperature boost is due to enhancement of the ion's kinetic energy or mobility.

\section{Statistical analysis in case of studying the effect of contact time}

Upon going through the (PWT) device, the brackish groundwater inflow is measured and re-analyzed after the outflow from this device. Knowing that, as shown in Table 3, the observable parameters of inflow water at room temperature are kept almost unchanged, the sample size (n) taken for analysis consists of five water samples from the outflow for 5, 10, 15, 20, and $25 \mathrm{~min}$. respectively, at $52.16 \mathrm{l} / \mathrm{min}$ and $12.32 \mathrm{l} / \mathrm{min}$ higher and lower flow rate. Mean, variance, and standard deviation 

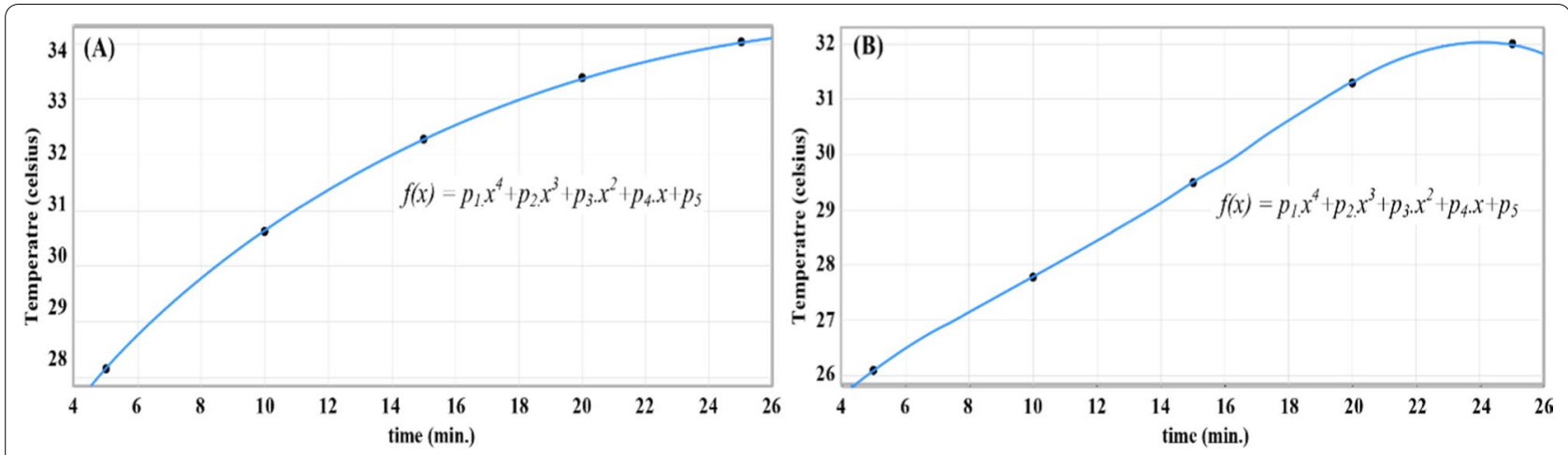

Fig. 7 Temperature vs. time, by using brackish groundwater in case of closed cycle: $\mathbf{A}$ at flow rate of $52.16 \mathrm{l} / \mathrm{min}$ and $\mathbf{B}$ at flow rate of $12.32 \mathrm{l} / \mathrm{min}$
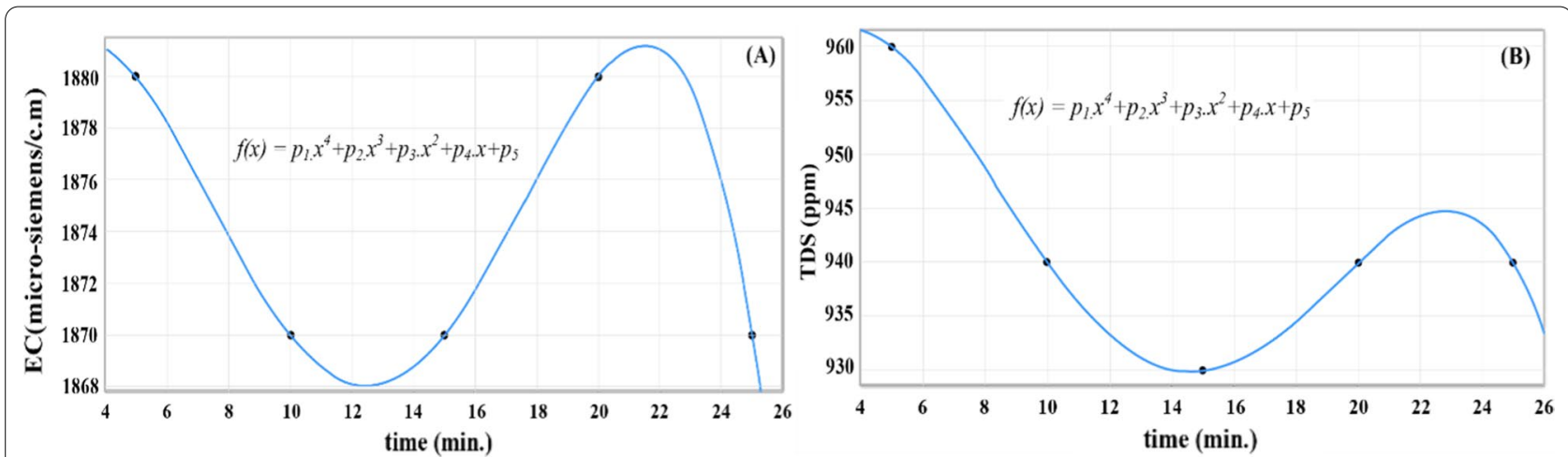

Fig. 8 Brackish groundwater in case of closed cycle at flow rate of 52.16 l/min: A electrical conductivity versus time and $\mathbf{B}$ total dissolved solids versus time
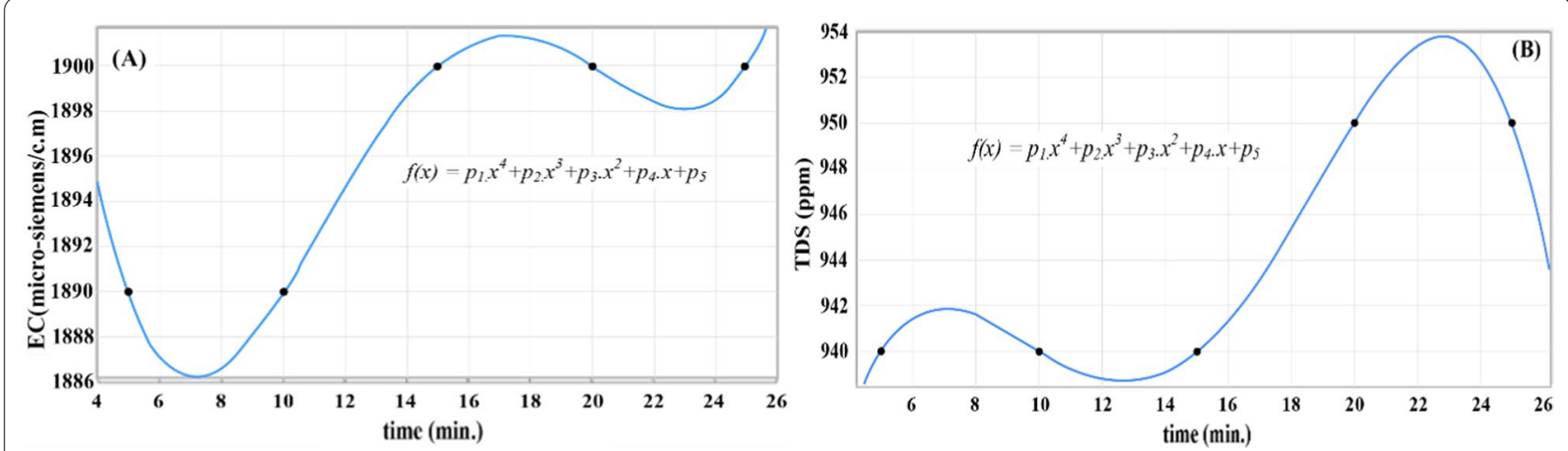

Fig. 9 Brackish groundwater in case of closed cycle at flow rate of $12.32 \mathrm{l} / \mathrm{min}$ : A electrical conductivity versus time and $\mathbf{B}$ total dissolved solids versus time

are determined as three descriptive statistics for this sample, in which:

- Sample Mean: is an average of the water parameter values for each.

- Sample Variance (Var. S): is the mean square deviations derived from this sample.
- Sample Standard Deviation (Stdev. S): is the square root of this sample variance, where it is a measure of how the values are spread out.

\section{Computational studies (DFT results)}

See Table 4. 


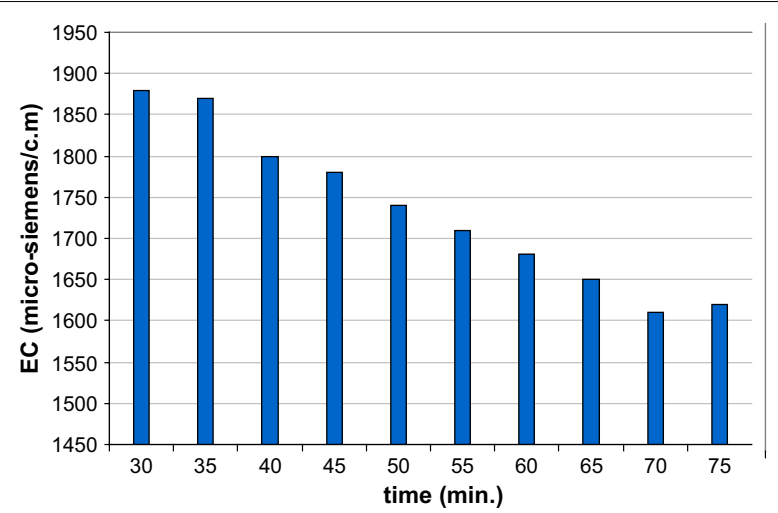

Fig. 10 Electrical conductivity versus time (30 min up to $75 \mathrm{~min}$ ), by using brackish groundwater in case of closed cycle at flow rate of $52.16 \mathrm{l} / \mathrm{min}$

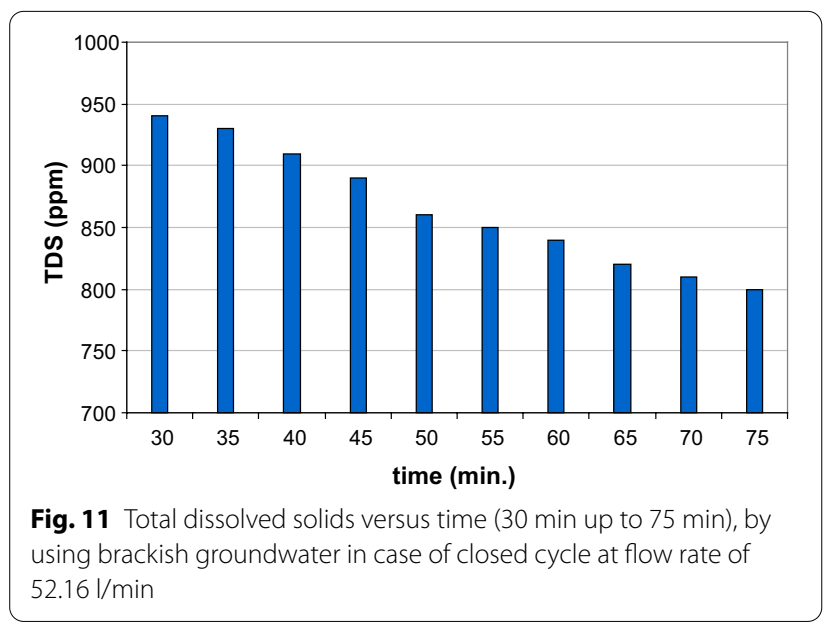

\section{Discussion}

\section{Outflow temperature}

It was discovered that a polynomial function represents the relationship between temperature vs time at the flow rate of $52.16 \mathrm{~L} / \mathrm{min}$. By plotting this relation, the polynomial function is found to be 4th degree with 5 coefficients (see Eq. 1).

$$
f(x)=p_{1} \cdot x^{4}+p_{2} \cdot x^{3}+p_{3} \cdot x^{2}+p_{4} \cdot x+p_{5}
$$

where $p_{1}=-1.333 \times 10^{-05}, p_{2}=0.001067, p_{3}=-0.04167$, $p_{4}=1.003, p_{5}=23.7$. Knowing that goodness of fit $(\mathrm{SSE})=5.68 \times 10^{-28}$, in which it refers to the sum of the squared errors of predication (deviations predicated from actual empirical values of data).

That is, SSE is a measure of the difference between the data given and an estimation model. A low SSE means that the mathematical model is in a close fit with the data collected. Using the first derivative test is a method for obtaining the critical points that cause a function to increase and decrease at them. Solve $f=0$; one of the three critical points, therefore, is 28.29. Therefore, since the feature increases to the left and decreases to the right of 28.29 , it must be that 28.29 is a maximum locale. It was concluded that at the time of 15 min the outflow from the PWT system is getting dry. This is consistent with what has been said regarding the effect of the apparent magnetic field on the water in which it limits the movement of the molecules of water and thus alters the liquid state thermal conduction. Besides this, the polynomial function of the relationship between temperature vs time is found at a flow rate of $12.32 \mathrm{l} / \mathrm{min}$ also has 5 coefficients at 4 th degree (see Eq. 2).

$$
f(x)=p_{1} \cdot x^{4}+p_{2} \cdot x^{3}+p_{3} \cdot x^{2}+p_{4} \cdot x+p_{5}
$$

where $p_{1}=-8.667 \times 10^{-05}, p_{2}=0.004467, p_{3}=-0.07983$, $p_{4}=0.9183, \mathrm{p}_{5}=23$, Knowing that goodness of fit $(\mathrm{SSE})=9.593 \times 10^{-28}$.
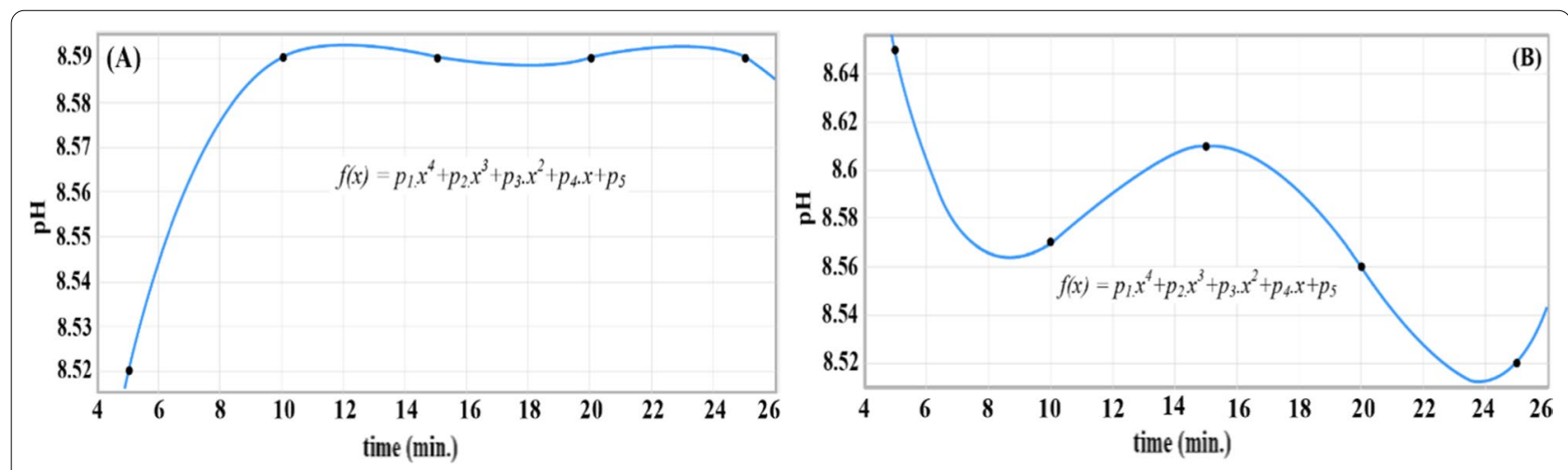

Fig. $12 \mathrm{pH}$ versus time, by using brackish groundwater in case of closed cycle: $\mathbf{A}$ at flow rate of $52.16 \mathrm{l} / \mathrm{min}$ and $\mathbf{B}$ at flow rate of $12.32 \mathrm{l} / \mathrm{min}$ 


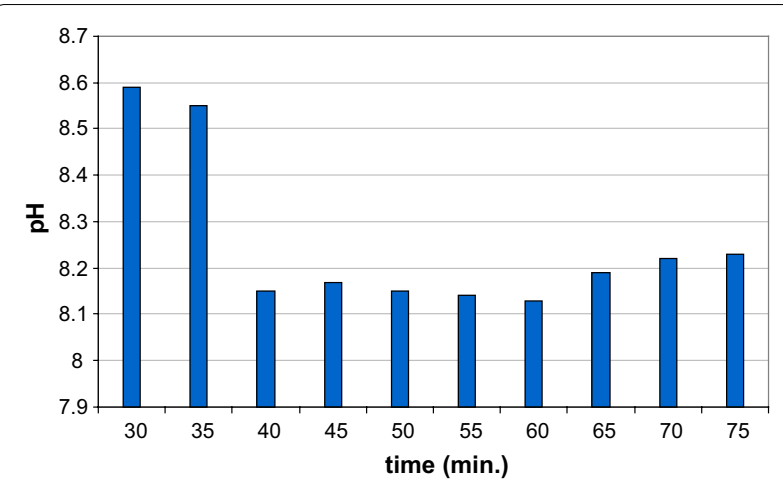

Fig. $13 \mathrm{pH}$ versus time (30 min. up to $75 \mathrm{~min}$ ), by using brackish groundwater in case of closed cycle at flow rate of $52.16 \mathrm{l} / \mathrm{min}$

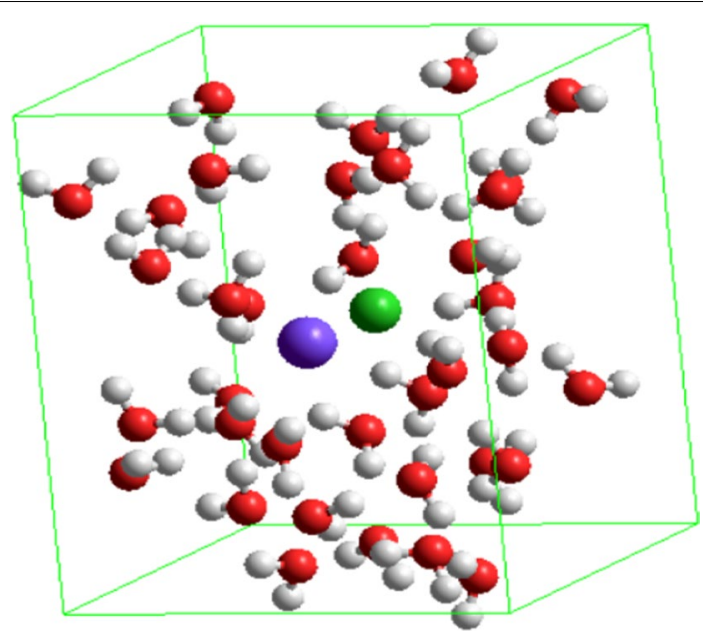

Fig. 14 A cubic simulation box of water- $\mathrm{NaCl}$, where $\mathrm{Cl}^{-}$ion is violet, $\mathrm{Na}^{+}$ion is green, oxygen is red, and hydrogen is white

\section{Outflow (EC and TDS)}

The relation between electrical conductivity (EC) versus time at $52.16 \mathrm{l} / \mathrm{min}$ flow rate in which the relation is expressed below (see Eq. 3) in the form of a fourth-degree polynomial function with five coefficients.

$$
f(x)=p_{1} \cdot x^{4}+p_{2} \cdot x^{3}+p_{3} \cdot x^{2}+p_{4} \cdot x+p_{5}
$$

where $\quad p_{1}=-0.002, \quad p_{2}=0.1, \quad p_{3}=-1.55$, $p_{4}=7.5, \quad p_{5}=1870$, Knowing that goodness of fit $(\mathrm{SSE})=1.913 \times 10^{-24}$.

One of the three deciding points is 28.59. Therefore, since the feature increases to the left and decreases to the right of 28.59, it must be that 28.59 is a maximum locale. Besides this, the polynomial function of the relation between total dissolved salts (TDS) vs time is observed at the same flow rate of $52,16 \mathrm{l} / \mathrm{min}$ and has 5 coefficients at the 4th degree (see Eq. 4).

$$
f(x)=p_{1} \cdot x^{4}+p_{2} \cdot x^{3}+p_{3} \cdot x^{2}+p_{4} \cdot x+p_{5}
$$

where $p_{1}=-0.002667, \quad p_{2}=0.1467, \quad p_{3}=-2.533$, $p_{4}=13.33, p_{5}=940$, knowing that goodness of fit $(\mathrm{SSE})=8.66 \times 10^{-25}$.

It has been discovered that there are three critical points where 3.73 and 22.9 are maximum local but 14.62 is a minimum local. Additionally, the polynomial function of the relationship between electrical conductivity (EC) vs. time at $12.32 \mathrm{l} / \mathrm{min}$ flow rate even has 5 coefficients in 4th degree (see Eq. 5).

$$
f(x)=p_{1} \cdot x^{4}+p_{2} \cdot x^{3}+p_{3} \cdot x^{2}+p_{4} \cdot x+p_{5}
$$

where $p_{1}=0.002, \quad p_{2}=-\quad 0.1267, \quad p_{3}=2.75$, $p_{4}=-22.83, p_{5}=1950$, knowing that goodness of fit $(\mathrm{SSE})=1.706 \times 10^{-24}$.

It has been found that there are three critical points where the local minimum is 7.16 and 23.09 , but 17.26 is a local maximum. Besides this, the polynomial function of the relationship between total dissolved salts (TDS) vs. time is discovered at the same flow rate of $12.32 \mathrm{l} / \mathrm{min}$ and also has 5 coefficients at 4th degree (see Eq. 6).

$$
f(x)=p_{1} \cdot x^{4}+p_{2} \cdot x^{3}+p_{3} \cdot x^{2}+p_{4} \cdot x+p_{5}
$$

where $\quad p_{1}=-0.002, \quad p_{2}=0.1133, \quad p_{3}=-2.15$, $p_{4}=16.17, p_{5}=900$, knowing that goodness of fit $(\mathrm{SSE})=9.564 \times 10^{-25}$.

\section{Outflow pH}

\begin{tabular}{|c|c|c|c|c|c|c|c|c|}
\hline & \multicolumn{8}{|c|}{5 samples for each flow rate of } \\
\hline & \multicolumn{4}{|l|}{$52.16 \mathrm{I} / \mathrm{min}$} & \multicolumn{4}{|c|}{$12.32 \mathrm{l} / \mathrm{min}$} \\
\hline & Temp $\left({ }^{\circ} \mathrm{C}\right)$ & $\mathrm{EC}(\mu \mathrm{S} / \mathrm{cm})$ & TDS (ppm) & $\mathrm{pH}$ & $\operatorname{Temp}\left({ }^{\circ} \mathrm{C}\right)$ & $\mathrm{EC}(\mu \mathrm{S} / \mathrm{cm})$ & TDS (ppm) & $\mathrm{pH}$ \\
\hline Average & 31.66 & 1874 & 942 & 8.576 & 29.34 & 1896 & 944 & 8.582 \\
\hline Var.S & 6.623 & 30 & 120 & 0.00098 & 5.953 & 30 & 30 & 0.00247 \\
\hline Stdev.S & 2.574 & 5.477 & 10.954 & 0.031 & 2.440 & 5.477 & 5.477 & 0.050 \\
\hline
\end{tabular}

This relationship is expressed in Eq. 7, and the form of polynomial function is 4 th with 5 coefficients.

Table 3 Statistical analysis for the outflow in case of closed cycle at the higher and lower flow rate 


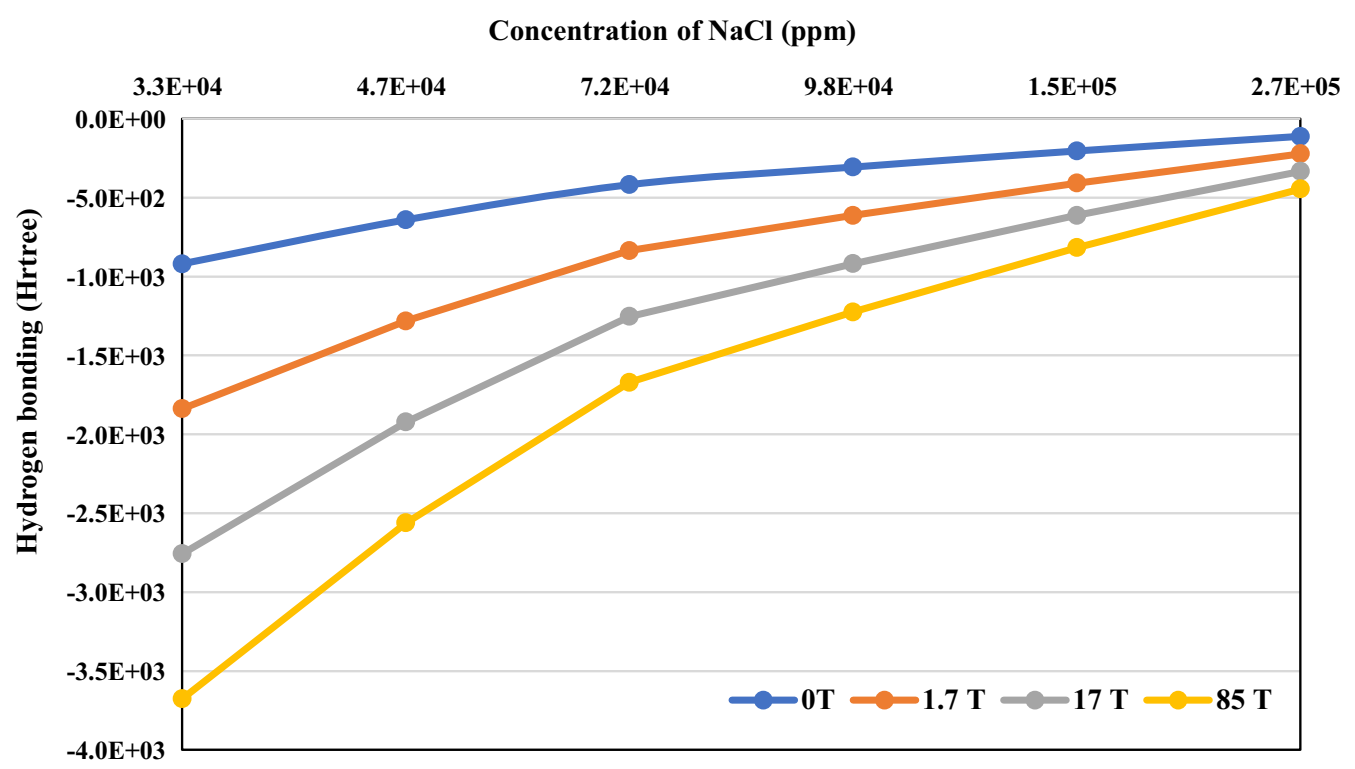

Fig. 15 Variation of hydrogen bonding versus PPM of water-NaCl system at different magnetic fields; $(0-1.7-17$ and $85 \mathrm{~T}$

$$
f(x)=p_{1} \cdot x^{4}+p_{2} \cdot x^{3}+p_{3} \cdot x^{2}+p_{4} \cdot x+p_{5}
$$

where $\quad p_{1}=-4.667 \times 10^{-06}, \quad p_{2}=0.0003267$, $p_{3}=-0.008283, p_{4}=0.08983, p_{5}=8.24$, knowing that goodness of fit $(\mathrm{SSE})=4.733 \times 10^{-29}$.

It was discovered that there are three critical points where the local limit is 11.92 and 23.13 but 17.45 is a local minimum. Moreover, the polynomial function of the relationship between $\mathrm{pH}$ vs. time at a flow rate of $12.32 \mathrm{l} / \mathrm{min}$ also has 5 coefficients in the 4th degree (see Eq. 8).

$$
f(x)=p_{1} \cdot x^{4}+p_{2} \cdot x^{3}+p_{3} \cdot x^{2}+p_{4} \cdot x+p_{5}
$$

where $p_{1}=2.067 \times 10^{-05}, p_{2}=-0.001313, p_{3}=0.02888$, $p_{4}=-0.2582, p_{5}=9.37$, knowing that goodness of fit $(\mathrm{SSE})=3.787 \times 10^{-29}$.

Table 4 Changes in binding energy (Hartree) of water molecules under external of magnetic field at different ppm of $\mathrm{NaCl}$ as seen in this table and the data are extracted from Fig. 15

\begin{tabular}{lllll}
\hline PPM & 0 T & 1.7 T & 17 T & 85 T \\
\hline $2.7 \mathrm{E}+05$ & -111.25417 & -111.25417 & -111.25469 & -111.25807 \\
$1.5 \mathrm{E}+05$ & -204.05773 & -204.05773 & -204.06083 & -204.07524 \\
$9.8 \mathrm{E}+04$ & -306.06784 & -306.06784 & -306.07101 & -306.08646 \\
$7.2 \mathrm{E}+04$ & -417.70080 & -417.70080 & -417.70139 & -417.72416 \\
$4.7 \mathrm{E}+04$ & -640.47932 & -640.47932 & -640.47917 & -640.47930 \\
$3.3 \mathrm{E}+04$ & -919.03901 & -919.03901 & -919.04166 & -919.06029 \\
\hline
\end{tabular}

Outflow temperature and its relationship with the other outflow parameters

Therefore, the electrical conductivity depends on these variables, and then, a change in the outflow temperature values results in variations in the EC outflow values. Therefore, variations in outflow $\mathrm{pH}$ values suggest that hydrolysis reaction may occur due to the ability to polarize ions (cation distortion/deformation or anion). Reaction to ionization occurs as inorganic salts dissolve in water, and these ions make up. Then, ions interact with $\mathrm{H}^{+}$or $\mathrm{OH}^{-}$, which constitute ionization of water molecules, knowing that two of these hydroxyl ions will form a water molecule $\left(\mathrm{H}_{2} \mathrm{O}\right)$ and give out a single oxygen atom. Hence, it can be assumed that breakage of water hydrogen bonds is due to the hydrolysis reaction process.

\section{Statistical analysis in case of studying the effect of contact time}

All these samples were analyzed using Microsoft Excel 2016 statistical analysis, which was determined to assess the mean, variance, and standard deviation. It should be noted that a low sample standard deviation means that the data points appear to be like the sample mean, while a high sample standard deviation means that the data points are distributed over a wider range. At the lower flow rate, the average $\mathrm{EC}$, TDS, and $\mathrm{pH}$ values of the outflow are more than the average EC, TDS, and $\mathrm{pH}$ values of the outflow at the higher flow. But the outflow temperature average value at the higher flow rate is greater than the outflow temperature average at the lower flow rate. 


\section{Computational studies (DFT results)}

The theoretical equation shows that the binding energy of the water molecules decreases as the applied magnetic field increases from 0 up to $85 \mathrm{~T}$. Also, it is observed that as the amount of water molecule increases or $\mathrm{NaCl} \mathrm{ppm}$ decreases, the energy of interaction is more negative. So, the bonding of hydrogen decreases as the magnetic field applied decreases.

\section{Conclusion}

The magnetization technique of the water is easy without consuming additional energy when a PWT device is utilized to create a permanent magnetic field $(\mathrm{B}=1.45 \mathrm{~T} \pm 0.05)$ during placing it on a previously setup water tube system. Thus, this environmentally friendly clean technology does not need further energy requirements. In addition, this technique leads to reviving water and its capability to soak up oxygen for returning the water to its vital qualities. It should be noted that the mechanism (or the theory) of magnetized water is summarized above. This study proved that the magnetic field has an influence on many water parameters in an open water system such as causing some fluctuations instantly in temperature, electrical conductivity, total dissolved solids, and $\mathrm{pH}$. For extra visualization, the statistical analysis was performed on a closed flow system as shown above in the results, and it was detected that there is an alteration in the value of standard deviation during exposing the inflow to (PWT) device. In general, $52.16 \mathrm{~L} /$ $\mathrm{min}$ (or $3.13 \mathrm{~m} 3 / \mathrm{hr}$ ) is the recommended flow rate in the case of an open cycle. But in the case of a closed cycle, the same previous flow rate is recommended at the time of $30 \mathrm{~min}$. It should be observed that the results were exposed to theoretical calculations by utilizing density functional theory. Therefore, magnetic water treatment is a method for treating the water physically and not considered as a technique for removing (or separating) the salts of water. In other words, it can be said that magnetic water treatment is a recent technique in which it is very paramount to become more advanced for achieving higher efficacy in lowering the effects of hard water.

\section{Abbreviations}

EC: Electrical conductivity; TDS: Total dissolved salts; PMF: Permanent magnetic field; PWT: Permanent water treatment; DFT: Density functional theory; PES: Potential energy surface.

\section{Acknowledgements}

Not applicable.

\section{Authors' contributions}

AM is the corresponding author, and he concerned with the idea and writing the paper. AA and EE are supervisors for the M.Sc. thesis. EA is concerned with the quantum research part. AG is a student of M.Sc., and he concerned with the practical work. All authors are conceived and planned the presented research. All authors read and approved the final manuscript.

Funding

Not applicable.

Availability of data and materials

The datasets used and/or analyzed during the current study are available from the corresponding author on reasonable request.

\section{Declarations}

Ethics approval and consent to participate

Not applicable.

Consent for publication

Not applicable.

\section{Competing interests}

The authors declare that they have no competing interests.

\section{Author details}

${ }^{1}$ Electrochemistry and Corrosion Laboratory, Physical Chemistry Department, National Research Centre, El-Bohouth St. 33, Dokki, P.O. 12622, Giza, Egypt. ${ }^{2}$ Electrical Power Department, Faculty of Engineering, Cairo University, Cairo, Egypt. ${ }^{3}$ Egyptian Petroleum Research Institute, 1 Ahmed El-Zomor Street-El-Zohour Region Nasr city, Cairo 11727, Egypt. ${ }^{4}$ Oroba Engineering Consultant Center, 14 Shurtat El-Zaitoun St., Gesr El-Suez, Heliopolis, Cairo, Egypt. ${ }^{5}$ Mechanical Design, and Production Department, Faculty of Engineering, Cairo University, Cairo, Egypt.

Received: 30 March 2021 Accepted: 1 June 2021

Published online: 08 June 2021

\section{References}

Alim F, Tlili MM, Amor MB, Maurin G, Gabrielli C (2009) Effect of magnetic water treatment on calcium carbonate precipitation: Influence of the pipe material. Chem Eng Process Process Intensif 48(8):1327-1332

Alimi F (2008) Anti-scale treatment of hard water by magnetic processes, PhD Thesis, National Institute of Applied Science and Technology, Tunisia, 2008

Ambashtaa DR, Sillanpaa M (2010) Water purification using magnetic assistance: a review. J Hazard Mater 180(1-3):38-49

Amor HB, Elaoud A, Hozayn M (2018) Does magnetic field change water pH. Asian Res J Agric 8(1):1-7

Andrianov A, Orlov E (2018) The assessment of magnetic water treatment on formation calcium scale on reverse osmosis membranes. MATEC Web of Conferences, Vol. 178, No. 2, Article ID 09001

Baker JS, Judd SJ (1995) Magnetic amelioration of scale formation. Water Res 30(2):247-260

Bogatin J, Bondarenko NP, Gak EZ, Rokhinson EE, Ananyev IP (1999) Magnetic treatment of irrigation water: experimental results and application conditions. Environ Sci Technol 33(8):1280-1285

Cho YI, Lee SH (2005) Reduction of the surface tension of water due to physical water treatment for fouling control in heat exchangers. Int Commun Heat Mass Transf 32(1-2):1-9

Dickinson SR, McGrath KM (2004) Aqueous precipitation of calcium carbonate modified by hydroxyl-containing compounds. Cryst Growth Des 4(6):1411-1418

Donaldson JD (1988) Magnetic treatment of fluids-preventing scale. Finishing $12(1)$

Elaoud A, Turki N, Amor HB, Jalel R, Salah NB (2016) Influence of the magnetic device on water quality and production of melon. Int $J$ Curr Eng Technol 6(6):2256-2260

El-Shamy AM, Farag HK, Saad W (2017) Comparative study of removal of heavy metals from industrial wastewater using clay and activated carbon in batch and continuous flow systems. Egypt J Chem 60(6):1165-1175 
El-Shamy AM, Abdelfattah I, Elshafey OI, Shehata MF (2018) Potential removal of organic loads from petroleum wastewater and its effect on the corrosion behavior of municipal networks. J Environ Manag 219:325-331

El-Shamy AM, El-Hadek MA, Nassef AE, El-Bindary RA (2020) Optimization of the influencing variables on the corrosion property of steel alloy 4130 in 3.5 wt. \% NaCl solution. J Chem 2020:1-20. Article ID 9212491

Emad El-Kashef AM, El-Shamy AA, Gad EAM, Gado AA (2019) Effect of magnetic treatment of potable water in looped and dead-end water networks. Egypt J Chem 62(8):1467-1481

Esmaeilnezhad E, Choi HJ, Schaffie M, Gholizadeh M, Ranjbar M (2017) Characteristics and applications of magnetized water as a green technology. J Clean Prod 161:908-921

Essa AK, El-Shamy AM, Reda Y (2018) Fabrication of commercial nanoporous alumina by low voltage anodizing. Egypt J Chem 61(1):175-185

Farag HK, El-Shamy AM, Sherif EM, El Abedin SZ (2016) Sonochemical synthesis of nanostructured $\mathrm{ZnO} / \mathrm{Ag}$ composites in an ionic liquid. Z Phys Chem 230(12):1733-1744

Golovleva VK, Dunaevskii GE, Levdikova TL, Sarkisov YS, Tsyganok YI (2000) Study of the influence of magnetic fields on the properties of polar liquids. Russ Phys J 43(12):1009-1012

Guo YZ, Yin DC, Cao HL, Shi JY, Zhang C, Liu YM, Huang HH, Liu Y, Wang Y, Guo WH, Qian AR, Shang P (2012) Evaporation rate of water as a function of a magnetic field and field gradient. Int J Mol Sci 13(12):16916-16928

Hachicha M, Kahlaoui B, Khamassi N, Misle E, Jouzdan O (2018) Effect of electromagnetic treatment of saline water on soil and crops. J Saudi Soc Agric Sci 17(2):154-162

Hogan V, Mason SE, Campbell SA, Walsh FC (1994) The use of magnetic fields in the prevention of scaling. UK Corrosion and Eurocorr 94, Bournemouth, UK, October 31-November 3, 1994

Iwasaka M, Ueno S (1998) Structure of water molecules under 14 T magnetic field. J Appl Phys 83(11):6459-6461

Jiang L, Zhang J, Li D (2015) Effects of permanent magnetic field on calcium carbonate scaling of circulating water. Desalin Water Treat 53(5):1275-1285

Kotb A, Aziz AMAE (2013) Scientific investigations on the claims of the magnetic water conditioners. Ann Fac Eng Hunedoara-Int J Eng 11(4):147-157

Kozic V, Lipus LC (2003) Magnetic water treatment for a less tenacious scale. J Chem Inf Comput Sci 43(6):1815-1819

Liu S, Yang F, Meng F, Chen H, Gong Z (2008) Enhanced anammox consortium activity for nitrogen removal: Impacts of static magnetic field. J Biotechnol 138(3-4):96-102

Mohamed AA, Khaled Z, El-Shamy AM, Sherif ZEA (2020) Utilization of 1-butylpyrrolidinium chloride ionic liquid as an eco-friendly corrosion inhibitor and biocide for oilfield equipment: combined weight loss, electrochemical and sem studies. Zeitschrift Für Physikalische Chemie Ahead of Publication. https://doi.org/10.1515/zpch-2019-1517

Mosin O, Ignatov I (2015) Magnetohydrodynamic cell for magnetic water treatment. Nanotechnol Res Pract 6(2):81-92

Nakagawa J, Hirota N, Kitazawa K, Shoda M (1999) Magnetic field enhancement of water vaporization. J Appl Phys 86(5):2923-2925

Paiaro G, Pandolfo L (1994) Magnetic treatment of water and scaling deposit. Anal Chim 84(5-6):271-274

Pandolfo L, Colale R, Paiaro G (1987) Magnetic field and tap water. La Chimica e L'industria 69(11):88-89
Park JS, Yang JH, Kim DH, Lee DH (2004) Degradability of expanded starch/PVA blends prepared using calcium carbonate as the expanding inhibitor. J Appl Polym Sci 93(2):911-919

Rajput S, Pittman CU Jr, Mohan D (2016) Magnetic magnetite $\left(\mathrm{Fe}_{3} \mathrm{O}_{4}\right)$ nanoparticle synthesis and applications for lead $\left(\mathrm{Pb}^{2+}\right)$ and chromium $\left(\mathrm{Cr}^{6+}\right)$ removal from water. J Colloid Interface Sci 468:334-346

Reda Y, El-Shamy AM, Zohdy KM, Eessaa A, K, (2020a) Instrument of chloride ions on the pitting corrosion of electroplated steel alloy 4130. Ain Shams Eng J 11(1):191-199

Reda Y, Zohdy KM, Eessaa AK, El-Shamy AM (2020b) Effect of plating materials on the corrosion properties of steel alloy 4130. Egypt J Chem 63(2):579-597

Shehata MF, Shaymaa EE-S, Nabila AA, El-Shamy AM (2019) Reduction of $\mathrm{Cu}^{+2}$ and $\mathrm{Ni}^{+2}$ ions from wastewater using mesoporous adsorbent: effect of treated wastewater on corrosion behavior of steel pipelines. Egypt J Chem 62(9):1587-1602

Shehata MF, El-Shamy AM, Zohdy KM, Sherif E-S, Abedin SZE (2020) Studies on the antibacterial influence of two ionic liquids and their corrosion inhibition performance. Appl Sci 10(4):1444

Sheikholeslami M, Rashidi MM, Hayat T, Ganji DD (2016) Free convection of magnetic nanofluid considering MFD viscosity effect. J Mol Liq 218:393-399

Tai CY, Wu CK, Chang MC (2008) Effects of magnetic field on the crystallization of $\mathrm{CaCO}_{3}$ using permanent magnets. Chem Eng Sci 63(23):5606-5612

Tomska A, Wolny L (2008) Enhancement of biological wastewater treatment by magnetic field exposure. Desalination 222(1-3):368-373

Wang Y, Babchin J, Chernyi LT, Chow RS, Sawatzky RP (1997) Rapid onset of calcium carbonate crystallization under the influence of a magnetic field. Water Res 31(2):346-350

Wang Y, Wei H, Li Z (2018) Effect of magnetic field on the physical properties of water. Results Phys 8:262-267

Watt DL, Rosenfelder C, Sutton CD (1993) The effect of oral irrigation with a magnetic water treatment device on plaque and calculus. J Clin Periodontol 20(5):314-317

Yamashita M, Duffield C, Tiller WA (2003) Direct current magnetic field and electromagnetic field effects on the $\mathrm{pH}$ and oxidation-reduction potential equilibration rates of water. 1. Purified water. Langmuir 19(17):6851-6856

Zaidi NS, Sohaili J, Muda K, Sillanpaa M (2014) Magnetic field application and its potential in water and wastewater treatment systems. Sep Purif Rev 43(3):206-240

Zlotopolsk V (2017) The impact of magnetic water treatment on salt distribution in a large unsaturated soil column. Int Soil Water Conserv Res 5(4):253-257

Zohdy KM, El-Sherif RM, Ramkumar S, El-Shamy AM (2021) Quantum and electrochemical studies of the hydrogen evolution findings in corrosion reactions of mild steel in acidic medium. Upstream Oil Gas Technol 6:100025

\section{Publisher's Note}

Springer Nature remains neutral with regard to jurisdictional claims in published maps and institutional affiliations.

\section{Submit your manuscript to a SpringerOpen ${ }^{\odot}$ journal and benefit from:}

- Convenient online submission

- Rigorous peer review

- Open access: articles freely available online

- High visibility within the field

- Retaining the copyright to your article

Submit your next manuscript at springeropen.com 